\title{
ERRATUM
}

D. N. Bateman · J. Chick · A. M. Good · C. A. Kelly

G. Masterton

\section{Are selective serotonin re-uptake inhibitors associated with an increased risk of self-harm by antidepressant overdose?}

\section{Eur J Clin Pharmacol (2004) 60:221-224}

It has come to our attention that an error was made in one calculation in respect of the above paper. As a result the likelihood ratio published is incorrect. The correct likelihood ratios for admissions involving venlafaxine shown in Table 1 (and also in the abstract) is $0.97(0.81$ $1.16)$, not 1.33 (1.13-1.55).

This error does not alter the main findings of the manuscript or any of the overall conclusions that we reached.

The online version of the original article can be found at http:// dx.doi.org/10.1007/s00228-004-0748-x

D. N. Bateman $(\bowtie) \cdot A$. M. Good · C. A. Kelly

Scottish Poisons Information Bureau (NPIS Edinburgh),

Royal Infirmary of Edinburgh, 51 Little France Crescent,

EH10 4SA Edinburgh, Scotland

E-mail: spib@1uht.scot.nhs.uk

Tel.: + 131-242-1383

Fax: + 131-242-1387

G. Masterton

Department of Psychological Medicine,

Royal Infirmary of Edinburgh, EH16 4SA

Edinburgh, Scotland

J. Chick

Royal Edinburgh Hospital,

EH10 5HF Edinburgh, Scotland 